\title{
ECONOMICA
}

Jurnal Program Studi Pendidikan Ekonomi

STKIP PGRI Sumatera Barat Vol.9 No.2 (133-142)

\section{THE IMPACT OF GREEN HUMAN RESOURCES ON ECONOMIC PERFORMANCE; MEDIATED BY GREEN INPUT AND OUTPUT}

\author{
By \\ Yasri $^{1)}$, Igura Metu Lengsi ${ }^{2)}$, Mia Ayu Gusti ${ }^{3)}$, Sumiati $^{4)}$ \\ 1) Lecturer of Master's Program in Management, Universitas Negeri Padang \\ Email: yasri33@fe.unp.ac.id \\ 2) Master's Program in Management, Universitas Negeri Padang \\ Email: iguralengsi@yahoo.com \\ ${ }^{3)}$ Master's Program in Management, Universitas Negeri Padang \\ Email: ayugustimia@gmail.com \\ 4) Master's Program in Management, Universitas Negeri Padang \\ Email: sumiati.unp@gmail.com \\ Submitted:2020.12.09 Reviewed:2021.04.20 Accepted:2021.04.29 \\ https://doi.org/10.22202/economica.2021.v9.i2.4554
}

\begin{abstract}
This study aims at empirically examining the role of GHRM in mediating the effect of green input and output on economic performance. This research used a quantitative approach. The population was SMIs (small and medium-sized industries) registered at the Ministry of Industry in West Sumatra. 200 SMIs were taken as the sample using a stratified proportional random sampling technique. The data were analyzed using a structural equation modeling technique with Smart-PLS. The results show that (i) the green HRM has an effect on green input, green output and economic performance; (ii) the green output has an effect on economic performance, but the green input has no effect on economic performance; and (iii) the green output mediates the relationship between green HRM and economic performance, but the green input does not mediate the relationship between green HRM and economic performance.
\end{abstract}

Jel Classification:

O15; O44; Q01

Keyword: Green HRM, Green Input and Output, Economic Performance. 


\section{INTRODUCTION}

Economic development is closely related to the use of natural resources. However, the continuous use of natural resources without paying attention to their preservation will have a negative impact on the environment. Global warning and climate exchange are examples of the already alarming impacts of natural exploitation. Facing changes in weather patterns in the world due to human activities, environmental groups have appealed to environmental protection, holding people accountable for destructive behavior that affects the earth (Yu-chen, W. S.-I. \& W, 2013). As a result, companies are required to be responsible and greener. The phenomena of environmental damage described above certainly encourage any organization to practice green human resource management (GHRM). In this context, the role of GHRM provides guidance on the strategy, vision and goals of the organization. GHRM is able to improve financial performance and increase employee commitment to be friendly to the environment (Korschun, Bhattacharya, \& Daniel, 2009).

SMIs are small and medium-sized industries that play their role in regional economic development in increasing the per capita income of the community. Besides, SMIs are also able to significantly absorb a very high number of workers because it is a labor-intensive industry. Although the activities of SMIs can increase the economic growth of the community, they might also cause environmental damage such as pollution, flooding and water pollution. The constraints in carrying out the production activities due to capital issues, marketing, and achieving high profits make small and medium-sized industries ignore environmental problems.

Small-, medium-, and large-sized enterprises have contributed to environmental problems in the form of pollution, waste gas, liquid and solid (Agan, Fatih, \& Borodin, 2013). Based on the author's observations, the cracker industry practice in Payakumbuh generally still disposed its industrial waste into a river, and so did the practice of tofu industry located in
Padang City. To overcome such waste disposal problems, several efforts have been made by the government, one of which is supervision in waste management. However, the supervision is not yet adequate and optimal due to irregular periodic inspection, ineffective socialization and limited available budget. Consequently, any parties involved in small and medium-sized industries should encourage the industries to create a friendly environment and investors to create environmentally friendly products, viewed from both their input and output.

Green programs will improve the sustainability of the performance of the industry (Chang, 2009). GHRM creates a good work environment to reduce the workers' fatigue, absenteeism, and shift which eventually reduce the operational costs. For example, using less paper and distributing and recording information online can reduce waste and costs (Hosain \& Rahman, 2016). In a production process, an industry generates waste and garbage that badly endanger humans and their environment. Therefore it is important to create green organization that follows green business procedures such as the application of green HRM in the production process (Bhutto \& Phil, 2016). To make a green organization must involve natural commodities or products, renewable products, reduction of the use of plastics, environmentally friendly labeling, and so forth (Chang, 2015). This leads to the necessity of implementing green HRM in the organization which will eventually create environmentally friendly products (Daily, Bishop, \& Massoud, 2012).

Companies that implement green HRM practices will enjoy benefits at the national and international levels by achieving significant savings from the use of renewable and environmentally friendly raw materials (Anu \& Shikha, 2015). The implementation of green HRM will benefit the company by reducing unnecessary costs, increasing the efficiency of the use of raw materials for not causing residual materials from the production process, improving environmental performance, and enhancing the company's image (Bangwal, Tiwari, \& 
Chamola, 2017). Green output can be seen from the consumer market side to market green products (Souza, Lamb \& Peretiatkos, 2003). Green product innovation has been recognized as one of the keys to success in achieving growth, environmental sustainability, and a better quality cycle. Understanding green product innovation as a result of the interaction between innovation and sustainability has become a priority strategy from both theoretical and practical basis (Dangelico, 2010).

The increasingly tight competition requires a product to have a competitive advantage, offering either lower cost product or differentiation such as product with high quality. In order for a company to be able to compete, the resulting product must be of high quality. Therefore, the company must ensure that the input provided by suppliers is of high quality (Chen et al., 2004, Yeung, 2008). As the quality or performance of the product (output) can only be good if the quality (performance) of the input is also good (Forker, 1999), the company must choose a supplier of input with good performance that would guarantee the provision of quality input. A number of companies went bankrupt because they were unable to produce quality output as a result of bad input provided by suppliers, leading to their failure to meet customer's expectations (Gabriel \& Bwisa. 2014).
The input logistics is largely determined by the quality of the supplier, and the quality of the logistical process has a strong influence on the efficiency of the input syllogistic. This means that there is a significant influence of input logistics on the quality and cost of the resulting output (Audy et. al., 2010). The quality of the input determines the quality of the output, thereby preventing product withdrawals from the market. Product withdrawals from the market are mostly due to unqualified input provided by suppliers or other factors from the company itself (Kumar \& Schmitz, 2011; Thirumalai \& Sinha, 2011). Therefore the implementation of integrated quality management starting from suppliers is very important in improving the quality of products and processes (Huo, Zhao, \& Lai, 2014; Zhang et al., 2017). Devaraj, Krajewski, and Wei (2007) found that the integration of input logistics has a significant effect on the output quality. Furthermore, Dey et al. (2015) found that input logistics management has an effect on the organizational performance. Quality supplier management affects the quality of the output. Thus, the quality management of input suppliers is an important key in producing quality output (Zsidisin et al., 2016; Lee \& $\mathrm{Li}, 2018)$. Then, the conceptual framework of this study is formulated as follows:

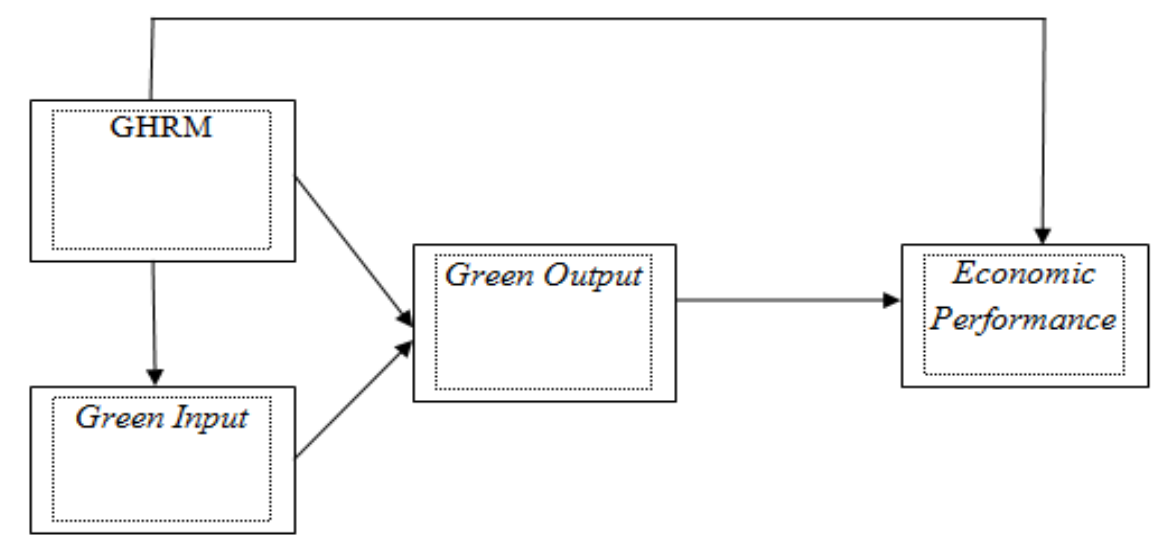

Figure 1. Conceptual framework 


\section{METHODS}

\section{Population and sample}

The population of this study was small and medium-sized industries (SMIs) located in West Sumatra that have been registered at the Department of Industry and Trade of West Sumatra Province. 200 SMIs were taken as the sample using a stratified random sampling technique. The sampling process was initiated by taking SMIs in 3 cities and 3 regencies in West Sumatra. Then, the sample representing the target SMI groups was taken, resulting in 200 SMIs.

\section{Measurement}

The questionnaire was developed based on the previous research. A five-point Likert scale - strongly disagree (1) to strongly agree (5) - was used in measuring the construction. This study used four constructs, including green HRM, green input, green output, and economic performance.

\section{Technique of data collection and analysis}

The data were collected using an onsite data collection technique. This was conducted using a survey method employing a questionnaire as the instrument of data collection and the trained people as the helper. This study was a cross sectional study where the data were collected in one time period. Then the data were analyzed using a Structural Equation Modeling (SEM) with Smart-PLS. First, the validity and reliability of the latent variables were tested using the measurement model analysis and then the hypotheses were tested using the structural model analysis.

\section{RESULTS AND DISCUSSION \\ Results \\ Measurement Model}

The first step in this research was assessing the validity and reliability as well as the discriminant validity. The indicator validity assessment can be seen from the outer loading value. The indicator is considered valid if the outer loading value is > 0.5 (Hair, Black, Babin, \& Anderson, 2010). Meanwhile, the reliability value can be seen from the composite reliability (CR) whose value is $>0.7$ (Hair, Hult, Ringle, \& Sarstedt, 2013), and the AVE (average variance extracted) value is $>0.5$ (Hair, et al.
2010), as shown in Table 1. This study also tested the discriminant validity by using the heterotrait-monotrait ratio of correlation (HTMT) evaluation (Hair, et al., 2010). Using HTMT as the criterion for accessing discriminant validity required the researchers to compare it with the predetermined threshold. Therefore, if the HTMT value is greater than the predetermined threshold, the researchers can conclude that discriminant validity does not exist. This study used a conservative threshold of 0.85 (Hair, et al. 2010) as listed in Table 2.

\section{Structural Model}

The structural model was performed by bootstrapping the 200 samples to determine whether each of these path analyses was significant or insignificant. The significant relationship in each path would be found if the $t$ statistical value $>$ 1.96 and the significance value (P value) < $5 \%$ (Hair, et al. 2010) which can be seen in Table 3 . The next process was the $\mathrm{R}$ square test. The $\mathrm{R}$ square value for the green input was 0.528 , meaning that $52.8 \%$ of the green input was explained by the green HRM. Next, the $\mathrm{R}$ square green output value was 0.627 , meaning that $62.7 \%$ of the green output was explained by the green HRM. Then, the $\mathrm{R}$ square economic performance value was 0.669 , meaning that $66.9 \%$ of the economic performance was explained by the green input and green output (green product). 
Table 1. Results of Measurement Model

\begin{tabular}{|c|c|c|c|c|}
\hline Construct model & $\begin{array}{l}\text { Measurement } \\
\text { Items }\end{array}$ & Outer Loading & AVE & $\mathrm{CR}$ \\
\hline \multirow[t]{10}{*}{ Green HRM } & GHRM 1 & 0.576 & \multirow[t]{10}{*}{0.587} & \multirow[t]{10}{*}{0.934} \\
\hline & GHRM 2 & 0.782 & & \\
\hline & GHRM 3 & 0.797 & & \\
\hline & GHRM 4 & 0.814 & & \\
\hline & GHRM 5 & 0.813 & & \\
\hline & GHRM 6 & 0.815 & & \\
\hline & GHRM 7 & 0.775 & & \\
\hline & GHRM 8 & 0.744 & & \\
\hline & GHRM 9 & 0.752 & & \\
\hline & GHRM 10 & 0.766 & & \\
\hline \multirow[t]{6}{*}{ Green Input } & GI 1 & 0.715 & \multirow[t]{6}{*}{0.629} & \multirow[t]{6}{*}{0.910} \\
\hline & GI 2 & 0.830 & & \\
\hline & GI 3 & 0.794 & & \\
\hline & GI 4 & 0.843 & & \\
\hline & GI 5 & 0.738 & & \\
\hline & GI 6 & 0.829 & & \\
\hline \multirow[t]{10}{*}{ Green output } & GO 1 & 0.675 & \multirow[t]{10}{*}{0.503} & \multirow[t]{10}{*}{0.910} \\
\hline & GO 2 & 0.663 & & \\
\hline & GO 3 & 0.770 & & \\
\hline & GO 4 & 0.624 & & \\
\hline & GO 5 & 0.661 & & \\
\hline & GO 6 & 0.700 & & \\
\hline & GO 7 & 0.769 & & \\
\hline & GO 8 & 0.786 & & \\
\hline & GO 9 & 0.724 & & \\
\hline & GO 10 & 0.699 & & \\
\hline \multirow{10}{*}{$\begin{array}{l}\text { Economic } \\
\text { Performance }\end{array}$} & EP 1 & 0.759 & \multirow[t]{10}{*}{0.520} & \multirow[t]{10}{*}{0.915} \\
\hline & EP 2 & 0.749 & & \\
\hline & EP 3 & 0.711 & & \\
\hline & EP 4 & 0.724 & & \\
\hline & EP 5 & 0.729 & & \\
\hline & EP 6 & 0.755 & & \\
\hline & EP 7 & 0.767 & & \\
\hline & EP 8 & 0.659 & & \\
\hline & EP 9 & 0.698 & & \\
\hline & EP 10 & 0.650 & & \\
\hline
\end{tabular}

Source: Prepared by the researchers

Table 2. Discriminant Validity Construct

\begin{tabular}{lllll}
\hline Construct & $\begin{array}{l}\text { Economic } \\
\text { Performance }\end{array}$ & Green Input & $\begin{array}{l}\text { Green } \\
\text { Output }\end{array}$ & Green HRM \\
\hline Economic Performance & & & & \\
Green Input & 0.758 & & & \\
Green Output & 0.862 & 0.865 & & \\
Green HRM & 0.775 & 0.801 & 0.861 & \\
\hline
\end{tabular}

Source: Prepared by the researchers 
Table 3. Summary of Path Coefficients

\begin{tabular}{|c|c|c|c|c|c|c|}
\hline & $\begin{array}{c}\text { Original } \\
\text { Sample } \\
\text { (O) }\end{array}$ & $\begin{array}{l}\text { Sample } \\
\text { Mean } \\
\text { (M) }\end{array}$ & $\begin{array}{l}\text { Standard } \\
\text { Deviation } \\
\text { (STDEV) }\end{array}$ & $\begin{array}{c}\mathrm{T} \\
\text { Statistics } \\
(\mid \\
\text { O/STDEV } \\
\mid) \\
\end{array}$ & $\begin{array}{c}\mathrm{P} \\
\text { Values }\end{array}$ & Explanation \\
\hline $\begin{array}{l}\text { GHRM -> } \\
\text { EP }\end{array}$ & 0.354 & 0.362 & 0.079 & 4.457 & 0.000 & $\begin{array}{l}\text { Hypothesis is } \\
\text { accepted }\end{array}$ \\
\hline $\begin{array}{l}\text { GHRM -> } \\
\text { GO }\end{array}$ & 0.506 & 0.505 & 0.074 & 6.884 & 0.000 & $\begin{array}{l}\text { Hypothesis is } \\
\text { accepted }\end{array}$ \\
\hline $\begin{array}{l}\text { GHRM -> } \\
\text { GI }\end{array}$ & 0.719 & 0.725 & 0.048 & 14.865 & 0.000 & $\begin{array}{l}\text { Hypothesis is } \\
\text { accepted }\end{array}$ \\
\hline GI $->$ GO & 0.377 & 0.381 & 0.072 & 5.250 & 0.000 & $\begin{array}{l}\text { Hypothesis is } \\
\text { accepted }\end{array}$ \\
\hline $\mathrm{GO}->\mathrm{EP}$ & 0.519 & 0.514 & 0.076 & 6.802 & 0.000 & $\begin{array}{c}\text { Hypothesis is } \\
\text { accepted }\end{array}$ \\
\hline
\end{tabular}

Source: Prepared by the researcher

From the results described above, it is concluded that all the direct effects are accepted because the $T$ statistic value is greater than 1.96 and the $\mathrm{P}$ value is less than $5 \%$.

\section{Mediation Testing}

In this study, the mediation testing used the method proposed by Hair et al. (2010) explaining that a mediating effect occurs when the direct effect is significant. The significant direct effects found in this study are the effect of green HRM on green output and the effect of green output on economic performance. This means that there is full mediation on the green output. The green input mediates the relationship between the green HRM and the green output because the direct effect of the green HRM on the green input and the direct effect of the green input on the green output are significant. Thus, there is a mediating effect on the green input and green output.

\section{Discussion}

The results of this study indicate that the green HRM affects the green input and green output (green product) thus supporting the two hypotheses. The application of green HRM concept has previously been highlighted in organizations because it tends to provide benefits and have a positive impact on the employee performance, the organization and the environment. In particular, the application of green HRM improves the environmental management system such as the efficient use of raw materials, the reduction of the remaining material from the production process, and the creation of environmentally friendly products (Bangwal, Tiwari, \& Chamola, 2017). To create an environmentally friendly production process, small and mediumsized industries (SMIs) have defined environmentally friendly values such as customer orientation, integrity, environmental performance/results, sustainability, human openness, and inclusion. These environmentally friendly values become the guidelines for implementing the green HRM concept. So, green HRM is a driving factor in creating environmentally friendly SMIs because, in addition to these values, the implementation of green HRM also holds the principles of reduce and reuse that will have an impact on the use of raw materials for the products and the resulting products. The same concept has also been reported in the previous study that the company holds 
the principles of reduce and reuse in implementing the green HRM concept (Chang, 2015). The implementation of such principle can be seen in the production process. In the input process, the workers make efficient use of raw materials, such as utilizing the remaining raw materials by turning them into additional products that do not damage the environment and bring benefits to the SMIs. This means that environmentally friendly workers will use the raw materials efficiently. Raw materials are the input in the production process, and a lot of remaining raw materials will result in losses both to the environment and SMIs. This indicates that the attention of environmentally friendly workers is not only addressed to environmental aspects but also to profit and social aspects. In addition to damaging the environment, a lot of remaining raw materials incurs a lot of costs to the SMIs.

The implementation of green HRM can lead to better economic performance, thus supporting the hypothesis in this study. This finding is in line with the findings of previous studies that green HRM can reduce costs. The example of efficient use of raw materials performed by the workers can cut unnecessary costs and ultimately improve economic performance (Hosain \& Rahman, 2016). This means that implementing green HRM can improve economic performance because it is relating to the various efficiencies carried out by SMIs. Hence, the key to implementing green HRM is efficiency, both the efficiency related to the environment and the efficiency related to the company's increased profits. This finding confirms the previous research findings arguing that the implementation of green HRM will produce various efficiencies such as the transition from paper-based industries to online-based industries (Kumar \& Schmitz, 2011). From the description above, it is concluded that the many results obtained from the application of green HRM are improving organizational performance through efficient use of resources (paper, raw materials, and other materials), cutting unnecessary costs, enhancing the company's image as an environmentally friendly organization and improving economic and environmental performance.

The results of this study also emphasize that SMIs have understood and implemented green products through the use of natural and recyclable raw materials to produce environmentally friendly products. The results of the analysis show that green products have an effect on the economic performance of SMIs. This means that green products serve as a driving factor in creating the people's economy because they create opportunities and even new markets in achieving competitive advantage through the use of environmentally friendly products which in turn can affect the profits of people's businesses. This is confirmed by the results of the previous research arguing that green products have been recognized as one of the keys to success in achieving growth, environmental sustainability, and better quality cycle (Souza, Lamb, \& Peretiatkos, 2003). Therefore, environmentally friendly products are of great concern in today's business world because implementing green products can save energy, efficiently use the remaining materials, eliminate pollution, and protect health. The green product eventually becomes valuable product that helps increase the product quality, and the SMIs have the opportunity to define higher prices for their products and gain more profits.

However, the use of environmentally friendly raw materials does not affect economic performance in small and mediumsized industries because small industries are influenced by consumer demand. The results of this study are different from the results of the previous study (Raut, Luthra, Narkhede, Mangla, Gardas, \& Priyadarshinee, 2019) arguing that the use of environmentally friendly raw materials is a strategy to minimize the organization's supply chain to the environment in expanding its economic performance. It is different with the current 
pandemic condition, SMIs cannot apply environmentally friendly raw material strategy to gain profit. At the present time, the most important objective of SMIs is to survive, i.e. to continue gaining profit without which SMIs are impossible to survive. During this pandemic condition, many SMIs have gone out of business due to low consumer demand for products so that SMIs do not return on investment and cannot survive this condition.

\section{CONCLUSION}

SMIs are small and medium-sized industries that play a role in regional economic development in increasing the per capita income of the community. Its success is determined by implementing green HRM and creating environmentally friendly products. This proves that the implementation of green HRM has an effect on economic performance. The output of green HRM is resource efficiency including efficiency of raw materials. Then, the implementation of green HRM also affects the selection of environmentally friendly raw materials because green HRM holds the principle of reduce and reuse on the use of REFERENCES

Agan, Y., Fatih, M., \& Borodin, A. (2013). Drivers of environmental processes and their impact on performance : A study of Turkish SMEs. Journal of Cleaner Production, 51, 23-33. https: //doi.org/10.1016/j.jclepro.2012.12.04 3

Anu Singh, L., \& Shikha, G. (2015). Impact of Green Human Resource Factors on Environmental Performance in Manufacturing Companies: Society For Science and Nature, 6(1), 23-30.

Audy, J.-F., Lehoux, N., D'Amours, S., \& Rönnqvist, M. (2010). A framework for an efficient implementation of logistics collaborations. International Transactions in Operational Research. 19 (5), 633-657. doi: 10.1111/j.14753995.2010.00799.x raw materials. Furthermore, green HRM also affects the resulting products because the orientation of green HRM is environmentally friendly which eventually leads to the creation of environmentally friendly products. Environmentally friendly products have many benefits, one of which is reducing pollution that helps maintain good health. Therefore, the environmentally friendly products become valuable and the quality of the products increases. This makes SMIs have an opportunity to set high prices for their environmentally friendly products which, in turn, increase their profits. Profit is one of the aspects of environmentally friendly development in addition to environmental and social aspects. However, in the current pandemic condition, the main concern is the life of SMIs, i.e. focusing on gaining profit in order to survive in the current pandemic condition. Therefore, the strategy of using environmentally friendly raw materials does not affect economic performance. At the present time, the economic performance of SMIs is affected by the pandemic condition, so their main concern is gaining profit for their survival.

Bangwal, D., Tiwari, P., \& Chamola, P. (2017). Green HRM, work-life and environment performance. International Journal of Environment, Workplace and Employment, 4(3), 244.

https://doi.org/10.1504/IJEWE.2017.0 87808

Bangwal, D., Tiwari, P., \& Chamola, P. (2017). Green HRM, work-life and environment performance. International Journal of Environment, Workplace and Employment, 4(3), 244.

https://doi.org/10.1504/IJEWE.2017.0 87808

Bhutto, S. A., \& Phil, M. (2016). Effects of Green Human Resources Management on Firm Performance: An Empirical Study on Pakistani Firms. European 
Journal of Business and Management, 8(16), 2222-2839.

Chang, C. (2009). The relationships among corporate social responsibility, corporate image and economic performance of high-tech industries in Taiwan, 417-429. https://doi.org/10.1007/s11135-0079117-z

Chang, K. (2015). The impacts of environmental performance and propensity disclosure on financial performance: Empirical evidence from unbalanced panel data of heavypollution industries in China. Journal of Industrial Engineering and Management, 8(1), 21-36. https://doi.org/10.3926/jiem.1240

Chen, I.J., Paulraj, A., and Lado, A.A., 2004. Strategic purchasing, supply management and firm performance. Journal of Operations Management. 22 (5), 505-523.

Daily, B. F., Bishop, J. W., \& Massoud, J. A. (2012). The role of training and empowerment in environmental performance. International Journal of Operations \& Production Management, 32(5), 631-647. https:// doi. org/ 10.1108/01443571211226524

Dangelico, R. M. (2010). Mainstreaming Green Product Innovation : Why and How Companies Integrate, 471486.https://doi.org/10.1007/s10551010-0434-0

Devaraj, S., L. Krajewski, and J. C. Wei. 2007. Impact of eBusiness technologies on operational performance: The role of production information integration in the supply chain. Journal of Operational Management. 25 (6):1199-216. doi:10.1016/j.jom.2007.01.002

Forker, L. (1999), "Factors affecting supplier quality performance" Journal of operations management. Vol 15, pp 243-69.
Gabriel, Maina and H.M. Bwisa. Factors that Affect the Quality of Inputs in Manufacturing Organisations: A Case Study of Nampak Kenya Limited. International Journal of Academic Research in Business and Social SciencesOctober 2014, Vol. 4, No. 10 ISSN: 2222-6990.

Hair, J. F., Black, W. C., Babin, B. J., \& Anderson, R. E. (2010). Multivariate data analysis. New Jersey: Prentice Hall.

Hair, J. F., Hult, G. T. M., Ringle, C., \& Sarstedt, M. (2013). A primeron partial least squares structural equation modeling (PLS-SEM).Los Angeles: SAGE Publications.

Hosain, S., \& Rahman, S. (2016). Green Human Resource Management : A Theoretical Overview, 18(6), 5459.https://doi.org/10.9790/487X1806035459

Huo, B., X. Zhao, and F. Lai. 2014. Supply chain quality integration: Antecedents and consequences. IEEE Transactions on Engineering Management. 61 (1):38-51. doi:10.1109/TEM.2013.2278543.

Korschun, C. B. Bhattacharya \& Daniel Sankar Sen. 2009. Strengthening Stakeholder- Company Relationships Through Mutually Beneficial Corporate Social Responsibility Initiatives. Journal of Business Ethics, 1-36.257-272.

Kumar, S., \& S. Schmitz. 2011. Managing recalls in a consumer product supply chain -root cause analysis and measures to mitigate risks. International Journal of Production Research. 49:235-53. doi:10.1080/00207543.2010.508952.

Lee, H. H., \& C. Li. 2018. "Supplier Quality Management: Investment, Inspection, and Incentives." Production and 
Operations Management. 27 (2): $304-$ 322. doi:10.1111/poms.12802.

Raut, R. D., Luthra, S., Narkhede, B. E., Mangla, S. K., Gardas, B. B., \& Priyadarshinee, P. (2019). Examining the performance oriented indicators for implementing green management practices in the Indian agro sector. Journal of CleanerProduction.

Souza, C. D., Lamb, P., \& Peretiatkos, R. (2003). Green products and corporate strategy : An empirical investigation. https: //doi.org/ 10.1108/ 1746568061 0669825rg/ $10.1016 /$ j.ijbioma.2019.05.16811-21.

Thirumalai, S., \& K. K. Sinha. 2011. Product recalls in the medical device industry: An empirical exploration of the sources and financial consequences. Management Science. 57 (2):376-92. doi:10.1287/mnsc.1100.1267.

Yeung, A. C. L. (2008), "Strategic supply management, quality initiatives, and organizational performance", Journal of Operations Management. Vol. 26, pp. 490-502.

Yu-chen, W. S.-I. \& W. (2013). The influence of enterprises' green management awareness on green management strategy and organizational performance, 31 .

Zhang, M., H. Guo, B. Huo, X. Zhao, \& J. Huang. 2017. Linking supply chain quality integration with mass customization and product modularity. International Journal of Production Economics. doi:10.1016/j.ijpe.2017.01.011.

Zsidisin, G. A., B. Petkova, L. W. Saunders, and M. Bisseling. 2016. "Identifying and Managing Supply Quality Risk." The International Journal of Logistics Management. 27 (3): 908-930. doi:10.1108/IJLM-02- 20150043. 